\title{
The impact of sport activities on basic motor skills of children with autism
}

\author{
Huseyin O. ${ }^{\mathrm{ABCDE}}$ \\ Gaziantep University School of Physical Education and Sports, Gaziantep, Turkey
}

Authors' Contribution: A - Study design; B - Data collection; C - Statistical analysis; D - Manuscript preparation; E - Funds collection.

\begin{abstract}
Purpose:

Material:

This study aims to investigate the impact of sports training on basic motor skills of children with autism. The study included sixteen children with autism who were aged between 12-16 years. The study aims to present the difference between basic motor skills of children with autism before sports training and after taking sports training for 12 weeks. The study was conducted in experimental design and compared values before and after sports training. SPSS 23.0 statistics program was used to perform statistical assessment of the data. The non-parametric Wilcoxon test was used for intragroup changes of fine and gross motor development, balance, life skills and self-care test data in the test battery.

Results: $\quad$ At the end of a 12-week study, positive developments were observed in balance, catching, skipping, basic gymnastics, and some psychomotor and life skills, while no significant difference was observed in throwing skills. Based on daily life generalization, it can be said that the learned skills positively contribute to life standards of individuals with autism.

Conclusions: $\quad$ The study results show that exercise programs also develop the physical fitness levels of children with autism. At the end of a 12-week sports training, a positive development was seen in basic motor skills and life skills. It is thought that useful results can be obtained with such exercise programs.

Keywords: autism, child, sports training, basic motor skills, life.
\end{abstract}

\section{Introduction}

Autism spectrum disorder (ASD) is a life-long disorder that starts before the age of three, damages social interaction and communication, causes restricted and repetitive behaviors and prevents the development of the brain. ASD is a disorder characterized by impairment in social interaction and communication skills as well as restricted, repetitive patterns of behavior [1]. Speech difficulties, exceptional speech patterns and delays in language development might be observed in individuals with ASD $[2,3,4]$.

Approximately $50 \%$ of individuals with ASD exhibit severely inadequate expressive language functions and cannot develop self-expressive language skills throughout their lives $[5,6,7]$ and also have significant difficulties in communicating, making eye contact, social smiling, social interactions and using the language functionally [8, $9,10]$.

Several studies concluded that sports training had positive impacts on physical and motor developments $[11,12]$ self-confidence [13], cognitive functions [14], acquiring new skills and reduction of repetitive behaviors [15] and academic skills [16] of individuals with ASD.

It has been seen in many studies that sportive games were extremely effective in the development of social interaction and communication skills of individuals with ASD [17, 18, 19]. Sportive games are instinctive movements that strengthen the opinions and character of children, give joy and pleasure, and play a significant role in their physical developments. A game is an activity that the children do willingly and freely. The game is a source of happiness, develops children physically, spiritually and (C) Huseyin O. , 2019

doi:10.15561/18189172.2019.0305 mentally, and improves their senses and emotions, as well as skills.

Kohler, Anthony, Steighner, and Hoyson [20] investigated the level of social interaction with peers and teachers as well as of physical activities in four children with ASD in different game activities with peers. Koegel, Werner, Vismara, and Koegel, [21] showed that game activities for children with ASD positively increased both physical activity and social interactions. Delano and Snell [19] investigated the effectiveness of optional game activities in children with ASD. The study results indicated a positive improvement in social skills of the children with ASD.

In their study of determining the effect of aquatic exercises on children with ASD, Chu and Pan [21] demonstrated that aquatic exercises improved social interactions of the children with ASD with their teachers and other children, as well as their aquatic skills.

In a study investigating the effects of sports activities on self-care, gross and fine motor and language development of children with ASD, Berigel [22] found that sports activities had positive impacts on gross and fine motor skills, social skills and language development of children with ASD. In their study, Alexander, Dummer, Smeltzer and Denton [23] examined the impacts of social skill and sports program on social skills of adults with ASD. Results of the study showed that there were positive developments in social skills as well as eye contact skills of adults with ASD compared to pre-program.

In their study investigating whether or not exercise practices were effective on physical fitness, self-confidence and social interactions of children including those with ASD, Oriel, George and Blatt [24] reported positive 
developments in the skills of starting communication and reaction to communication in exercise sessions. Garcia-Villamisar and Dattilo [25] examined social and clinical impacts of leisure activities on individuals with ASD. Leisure activities including sports trainings were performed for one year. The study indicated positive changes in social and communication skills after the leisure activities.

In their study Gabriels, Agnew, Holt, Shoffner, Pan, Ruzzano and Mesibov [26] concluded that therapeutic horse-riding exercises caused positive changes in communication skills of children and young individuals with ASD. In a study with healthy children and children with ASD, Toon [27] found that athletic activities positively caused strong changes in healthy children's acceptance of, and attitude towards children with ASD.

In a study [25] it was found that teacher candidates who received physical education and sports training for disabled individuals had higher awareness levels regarding the effects of sports on individuals with mental incompetence, compared to those who did not receive such training. Carter, Messinger, Stone, Celimli, Nahmias and Yoder [27] concluded in their study that sportive activities positively contributed to the development of language skills in children with ASD. Recent studies also shown that athletic trainings were effective in conveying other branches of education in children with ASD [28, 29, 30].

\section{Purpose:}

This study was conducted with sixteen children with autism at the Youth and Sports Club for Development in Gaziantep to determine the impacts of a 12-week sports training on the development of basic motor skills and social interaction and communication skills of children with ASD.

\section{Material and Methods}

Participants: Sixteen children with autism who were diagnosed with autism by the CRC (Counseling and Research Center), received sports training via a oneto-one coaching system at the Youth and Sports Club for Development in Gaziantep, who had the below- mentioned prerequisite skills and were aged 12-16 years were included in the study. Informed consent forms were signed from all the subjects' parents. The present study was conducted in accordance with Helsinki Declaration.

\section{Research Design.}

A 12-week sports training program was prepared for the study, and balance, fine and gross motor skills, life skills and self-care tests were applied within this program to develop the basic motor skills of children with autism. The study comprised of sports trainings for four hours per day, five days a week.

Practitioners: Practitioners were sports trainers of the Youth and Sports Club for Development. Trainers in the study were experts who took part in one-to-one life coaching system for children with autism for many years.

Study Environment: The study was conducted in the sports hall of Gaziantep Youth and Sports Club for Development which is tailored to autistic children and is where training is given.

The practices conducted: Basic Sports Skills (balance, catching, throwing and skipping skills). Psychomotor Skills (Walking up and down the stairs and Jogging for at least 20 minutes). Gymnastics (eagle, single kneeling, tabletop, supported boat, side lunge poses). Coordination (ability to complete three and five-skill stations). Cycling (cycling on balance wheels, cycling with training wheels, cycling without support). Life Skills (Dressing and undressing, opening and closing hook-and-loop fasteners of shoes and tying shoelaces, zipping and unzipping skills were studied).

Statistical Analysis.

The statistical assessment of the data was performed by using the SPSS 23.0 statistical software program. An observation form and the non-parametric Wilcoxon test were used for intragroup changes of balance, fine and gross motor development, balance, life skills and self-care test data. The level of significance was selected as $p<0.05$ for comparisons.

\section{Results}

Personal details are provided in Table 1.

When Table 1 is examined, it is seen that nine female

Table 1.Physical Properties of Children with Autism Spectrum Disorder

\begin{tabular}{llll}
\hline Variables & Subgroups & Number $(\mathbf{n}=\mathbf{1 6})$ & Percentage (\%) \\
\hline Gender & Female & 9 & 56.6 \\
& Male & 7 & 43.8 \\
Age & 12 years old & 6 & 37.5 \\
& 13 years old & 4 & 25 \\
& 14 years old & 2 & 12.5 \\
Weight & 16 years old & 4 & 25 \\
& $30-50 \mathrm{~kg}$ & 9 & 56.3 \\
& $60-80 \mathrm{~kg}$ & 5 & 31.3 \\
Height & $81 \mathrm{~kg}$ and above & 2 & 12.5 \\
& $140-160 \mathrm{~cm}$ & 6 & 37.5 \\
\hline
\end{tabular}


and seven male individuals were enrolled in the study; six, four, two and four of them were 12, 13, 14 and 16 years old, respectively; and those with the weight and height of $30-50 \mathrm{~kg}$ and $161-190 \mathrm{~cm}$ were the majority.

When Table 2 is examined, positive statistical differences between pre-test and post-test are as follows: +1.31 points for static balance (standing on one foot for a minimum of 20 seconds), +2.72 points for dynamic balance (on the balance beam), +1.5 points for catching a ball with the right hand, +1.98 points for catching a ball with the left hand, +2.32 points for skipping with both feet for six circles in a row, +2.30 points for skipping on one foot (twice with the right foot, and twice with the left foot), +1.17 points for skipping with both feet from a height of $15 \mathrm{~cm},+2.95$ points for jogging for at least 20 minutes, +0.28 points for the eagle pose, +0.34 points for the single

Table 2. Results of Pre and Post-Test in Children with Autism Spectrum Disorder

\begin{tabular}{|c|c|c|c|c|c|c|c|}
\hline \multirow[t]{2}{*}{ Tests } & \multirow[t]{2}{*}{ Subgroups } & \multicolumn{2}{|c|}{$\begin{array}{l}\text { Pre-Test } \\
(n=16)\end{array}$} & \multicolumn{2}{|c|}{$\begin{array}{l}\text { Post-Test } \\
(n=16)\end{array}$} & \multicolumn{2}{|c|}{$\begin{array}{l}\text { Wilcoxon } \\
\text { Two Paired } \\
\text { Samples Test }\end{array}$} \\
\hline & & $\mathbf{x}$ & SD & $\mathbf{x}$ & SD & $\mathbf{Z}$ & $\mathbf{P}$ \\
\hline \multirow[t]{2}{*}{ Balance } & $\begin{array}{l}\text { Static balance (stands on one foot for minimum } \\
20 \text { seconds) }\end{array}$ & 1.17 & 0.69 & 2.48 & 0.79 & -2.52 & $0.01^{*}$ \\
\hline & Dynamic balance (balance beam) & 1.80 & 1.71 & 4.52 & 1.95 & -2.50 & $0.03^{*}$ \\
\hline \multirow[t]{3}{*}{ Catching } & Catching with both hands & 1.81 & 0.21 & 1.83 & 0.40 & -1.18 & 0.23 \\
\hline & Catching a ball with the right hand & 1.51 & 0.57 & 3.01 & 0.76 & -2.52 & $0.02^{*}$ \\
\hline & Catching a ball with the left hand & 1.04 & 0.43 & 3.02 & 0.59 & -2.10 & $0.03^{*}$ \\
\hline \multirow[t]{2}{*}{ Throwing } & $\begin{array}{l}\text { Throwing a tennis ball into a basket at a } \\
1.5 \text {-meter distance }\end{array}$ & 3.13 & 0.30 & 3.50 & 0.93 & -1.00 & 0.31 \\
\hline & $\begin{array}{l}\text { Throwing a table tennis ball into a basket at a } \\
\text { 2-meter distance }\end{array}$ & 1.62 & 0.30 & 1.75 & 0.48 & -0.58 & 0.56 \\
\hline \multirow[t]{3}{*}{ Skipping } & Skipping with both feet for six circles in a row & 1.47 & 0.53 & 3.79 & 0.45 & -2.52 & $0.02^{*}$ \\
\hline & $\begin{array}{l}\text { Skipping on one foot (twice with the right foot, } \\
\text { and twice with the left foot) }\end{array}$ & 1.30 & 0.50 & 3.60 & 0.78 & -2.52 & $0.01^{*}$ \\
\hline & Skipping with both feet from a height of $15 \mathrm{~cm}$ & 2.36 & 0.97 & 3.53 & 0.78 & -2.52 & $0.01^{*}$ \\
\hline \multirow[t]{2}{*}{ Psychomotor } & Ability to walk up and down stairs & 2.50 & 0.80 & 1.73 & 0.88 & -2.52 & $0.01^{*}$ \\
\hline & Ability to jog for at least 20 minutes & 1.45 & 0.57 & 4.40 & 0.67 & -2.53 & $0.01^{*}$ \\
\hline \multirow[t]{5}{*}{ Gymnastics } & Eagle pose & 2.00 & 1.56 & 2.28 & 1.73 & -2.52 & $0.01^{*}$ \\
\hline & Single kneeling pose & 1.55 & 1.15 & 1.89 & 1.16 & -2.52 & $0.01^{*}$ \\
\hline & Tabletop pose & 2.08 & 1.44 & 2.28 & 1.47 & -2.53 & $0.01^{*}$ \\
\hline & Supported boat pose & 1.13 & 0.50 & 1.50 & 0.61 & -2.52 & $0.01^{*}$ \\
\hline & Side lunge pose & 1.43 & 0.71 & 1.62 & 0.79 & -1.40 & $0.01^{*}$ \\
\hline \multirow[t]{2}{*}{ Coordination } & Ability to finish the three-skill station & 1.82 & 0.87 & 1.70 & 0.90 & -2.52 & $0.01^{*}$ \\
\hline & Ability to finish the five-skill station & 1.80 & 0.79 & 2.54 & 0.83 & -2.52 & $0.01^{*}$ \\
\hline \multirow[t]{3}{*}{ Cycling } & Cycling on balance wheels & 1.84 & 0.39 & 1.38 & 0.27 & -2.52 & $0.01^{*}$ \\
\hline & Cycling with training wheels & 2.44 & 0.41 & 1.87 & 0.47 & -2.52 & $0.01^{*}$ \\
\hline & Cycling without support & 1.99 & 0.36 & 1.46 & 0.34 & -2.52 & $0.01^{*}$ \\
\hline Life & Putting on and taking off shoes & 2.41 & 0.68 & 3.88 & 0.63 & -2.52 & $0.01^{*}$ \\
\hline \multirow[t]{6}{*}{ Skills } & Putting on and taking off socks & 2.41 & 0.77 & 3.78 & 0.59 & -2.52 & $0.01^{*}$ \\
\hline & $\begin{array}{l}\text { Putting on and taking off bottom clothing } \\
\text { (underwear, etc.) }\end{array}$ & 2.89 & 1.09 & 3.14 & 0.93 & -2.52 & $0.01^{*}$ \\
\hline & $\begin{array}{l}\text { Putting on and taking off upper clothing } \\
\text { (undershirt, etc.) }\end{array}$ & 2.65 & 1.03 & 3.11 & 0.88 & -2.52 & $0.01^{*}$ \\
\hline & $\begin{array}{l}\text { Opening and closing of shoes' hook-and-loop } \\
\text { fasteners }\end{array}$ & 2.02 & 0.39 & 3.49 & 0.34 & -2.52 & $0.01^{*}$ \\
\hline & Tying of shoelaces & 2.83 & 1.26 & 3.72 & 2.34 & -2.52 & $0.01^{*}$ \\
\hline & Zipping and unzipping clothes & 2.61 & 0.60 & 3.75 & 0.42 & -2.52 & $0.01^{*}$ \\
\hline
\end{tabular}

Notes: $p<0.05$ 
kneeling pose, +0.20 points for the tabletop pose, +0.37 points for the supported boat pose, +0.19 points for the side lunge pose, +0.38 points for the ability to finish the three-skill station, +0.74 points for the ability to finish the five-skill station, +1.47 points for putting on and taking off shoes, +1.37 points for putting on and taking off socks, +0.25 points for putting on and taking off bottom clothing items (all bottom clothing types), +0.46 points for putting on and taking off upper clothing items (all top clothing types), +1.47 points for opening and closing of shoes' hook-and-loop fasteners, +0.89 points for tying of shoelaces, and +1.14 points for zipping and unzipping of clothes.

Negative differences: There were statistical differences of -2.39 points, -0.46 points, -0.74 points and -0.53 points for walking up and down stairs, cycling on balance wheels, cycling with training wheels and cycling without support, respectively. Negative development of this result is attributed to the tiredness of children due to the practices.

Statistically significant differences: There was no significant difference for the skills of catching with both hands, throwing a tennis ball into a basket at a 1.5 meter distance and throwing a table tennis ball into a basket at a 2-meter distance. Positive development; but, given the positive results, given the results, it is seen that there is a positive development but no statistically significant difference.

According to the results of the study, the children exhibited development as "can do" and "can do well" after the training for the following skills:

- Balance: Static balance (standing on one foot for minimum of 20 seconds), Dynamic balance (balance beam).

- Catching: Catching a ball as big as a volleyball with the left hand and the right hand.

- Skipping: Skipping with both feet for six circles in a row, skipping on one foot (twice with the right foot, and twice with the left foot), skipping with both feet from a height of $15 \mathrm{~cm}$.

- Psychomotor: Walking up and down stairs, jogging for at least 20 minutes.

- Gymnastics: Eagle pose, single kneeling, tabletop, supported boat and side lunge poses.

- Coordination: Ability to finish the three-skill station, ability to finish the five-skill station.

- Life Skills: Putting on and taking off shoes, putting on and taking off socks, putting on and taking off bottom items of clothing (underwear, etc.), putting on and taking off upper items of clothing (undershirt, etc.), opening and closing shoes' hook-and-loop fasteners, tying shoelaces, zipping and unzipping clothes.

\section{Discussion}

In the study, a difference between pre-test and posttest results was found in the reactions of children with autism to the tests of balance, catching, throwing, skipping, psychomotor skills, gymnastics, coordination, cycling and life skills.
It was concluded that balance (static and dynamic balance) studies yielded successful results. In studies supporting these results, it was seen that the static and dynamic balance of children with autism are improved with the exercise program prepared for them [31]. An improvement in the balance development of children with autism after a 6-week exercise program focused on balance has been previously noted [32]. The impact of an 8 -week taekwondo exercise program on the balance of children with autism was examined and it was concluded that their balance had developed positively [33].

Catching: It was concluded that the skill of catching a ball as big as a volleyball with the left hand and the right hand was significantly improved. In studies supporting these results, it was seen that the skill of catching a ball with two hands was developed positively in children with autism [34, 35, 36].

Skipping: The skill of skipping with both feet for six circles in a row, skipping on one foot (twice with the right foot, and twice with the left foot), skipping with both feet to a height of $15 \mathrm{~cm}$ were improved. In studies supporting these results, the effects of an aquatic exercise program on the motor skills of children with autism were examined and a significant difference was found in jumping parameters [37]. In a study analyzing the effect of autism on jumping skills, it was noted that physical exercise significantly increases the jumping distance of children with autism [38].

Psychomotor: The skills of walking up and down stairs and jogging for a minimum 20 minutes were positively improved. In studies supporting these results, the effects of regular sports training on the personal skills of children with autism were examined and it was found that there were positive developments in this regard [39]. After analyzing the effect of a 12 -week exercise program on the gait of children with autism, significant improvements were found [40].

Gymnastics: It was found that there were positive developments in certain poses such as the eagle pose, single kneeling, tabletop, supported boat and side lunge poses. In studies supporting these results, it was concluded that a 10 -week program of aquatic exercises and swimming had positive effects on the motor skills and basic gymnastic poses of children with autism [41]. In a study investigating the impact of gymnastics on the motor skills of children with autism, a significant difference was found in the motor skills of children following gymnastic exercises [42].

Coordination: It was determined that the skills of finishing three-skill and five-skill stations were positively improved. In studies supporting these results, it was stated that motor disorders of children with autism exercising regularly were positively improved [43, 44].

Life Skills: After the training; the skills of putting on and taking off shoes, putting on and taking off socks, putting on and taking off bottom items of clothing (underwear, etc.), putting on and taking off upper items of clothing (undershirt, etc.), opening and closing shoes' hook-and-loop fasteners, tying shoelaces, zipping 
and unzipping clothes have been improved. In studies supporting these results, improvements were recorded in the self-care skills of children with autism such as putting on and taking off their clothes, using the toilet and taking a bath as a result of the sporting activities designed for these children $[45,46]$.

\section{Conclusion}

Based on the study results, it is seen that basic motor skills improve with regular sports training in children with autism. Generalized into daily life, the skills learned positively contribute to life standards of individuals with autism, and moreover, provide certain convenience, skills and self-confidence in life.

\section{Recommendations}

Preparation and implementation of sports training programs intended for individual inabilities of children with autism, directing them to branches which they like and succeed in through the selection of abilities, conducting studies to provide positive gains in their family lives and social lives, and raising the awareness of families, and supporting such studies through the use of social media and projects are recommended.

\section{Conflict of interest}

The author declares no conflict of interest.

\section{References}

1. American Psychiatric Association. Diagnostic and statistical manual of mental disorders (5th ed.). Washington: American Psychiatric Association; 2013. https://doi.org/10.1176/appi.books.9780890425596

2. KircaaliIftar G. Developing Communiction Skills for Childeren With Outism. Istanbul: YA-PA Publiacion; 2003.

3. Friend M. Special education: Contemporaray perspectives for school professionals. Boston: Pearson; 2006.

4. Kasari C, Rotheram-Fuller E, Locke J, Gulsrud A. Making the connection: randomized controlled trial of social skills at school for children with autism spectrum disorders. Journal of Child Psychology and Psychiatry, 2012; 53 (4): 431- 439. https://doi.org/10.1111/j.1469-7610.2011.02493.x

5. RutterM.Diagnosisanddefinition of childhoodautism.Journal of Autism and Childhood Schizophrenia, 1978; 8(2): 139- 161. https://doi.org/10.1007/BF01537863

6. Prizant BM. Language acquisition and communicative behaviorinautism:towardanunderstanding of the "whole" of it. Journal of Speech and Hearing Disorders, 1983; 48: 296- 307. https://doi.org/10.1044/jshd.4803.296

7. Lord C, Rutter M, Le Couteur A. Autism Diagnostic Interview-Revised: A revised version of a diagnostic interview for caregivers of individuals with possible pervasive developmental disorders. Journal of Autism and Developmental Disorders, 1994; 24: 659- 685. https://doi.org/10.1007/BF02172145

8. Sani Bozkurt S and Vuran S. An analysis of the use of social stories in teaching social skills to children with autism spectrum disorders. Educational Sciences, 2014; 14(5): 1875- 1892. https://doi.org/10.12738/estp.2014.5.1952

9. Reichow B, Doehring P, Cicchetti DV, Volkmar FR, editors. Evidence-Based Practices and Treatments for Children with Autism. Boston, MA: Springer US; 2011. https://doi.org/10.1007/978-1-4419-6975-0

10.Heward WL. Exceptional children: An introduction to special education (10th ed.). New Jersey: Pearson Merrill Prentice Hall; 2013.

11.Lotan M, Isakov E, Merrick J. Improving functional skills and physical fitness in children with Rett syndrome. Journal of Intellectual Disability Research, 2004; 48(8): 730-735. https://doi.org/10.1111/j.1365-2788.2003.00589.x

12.Pitetti KH, Rendoff AD, Grover T, Beets MW. The efficacy of a 9-month treadmill walking program on the exercise capacity and weight reduction for adolescents with severe autism. Journal of Autism and Developmental Disorders, 2007; 37(6): 997-1006. https://doi.org/10.1007/s10803-006-0238-3
13.Todd T, Reid G, Butler-Kisber L. Cycling for students with ASD: Self regulation promotes sustained physical activity. Adapted Physical Activity Quarterly, 2010; 27(3): 226-241. https://doi.org/10.1123/apaq.27.3.226

14.Anderson HC, Turek K, Schneiderman RL. Autism and Exergaming: Effects on repetitive behaviors and Cognitions. Psychology Research and BehaviorManagement, 2011; 4: 129-137. https://doi.org/10.2147/PRBM.S24016

15.Bahrami F, Movahedi A, Marandi SM, Abedi A. Kata techniques training consistently decreases stereotypy in children with autism spectrum disorder. Researchin Developmental Disabilities, 2012; 33(4): 1183-1193. https://doi.org/10.1016/j.ridd.2012.01.018

16. Nicholson H, Kehle TJ, Bray MA, Van Heest J. The effects of antecedent physical activity on the academic engagement of children with autism spectrum disorder. Psychology in the School, 2011; 48(2): 198-213. https://doi.org/10.1002/pits.20537

17.Dunlap LL. An introduction to early childhood special education birth to age five. New Jersey: Pearson; 2009.

18.Tsao LL. Social, language, and play behaviors of children with autism. Behavioral Development Bulletin, 2008; 14(1): 40-51. https://doi.org/10.1037/h0100506

19.Delano M, Snell ME. The effects of social stories on the social engagement of children with autism. Journal of Positive Behavior Interventions, 2006; 8(1): 29-42. https://doi.org/10.1177/10983007060080010501

20.Kohler FW, Anthony LJ, Steighner SA, Hoyson M. Teaching social interaction skills in the integrated preschool: An examination of naturalistic tactics. Topics in Early Childhood Special Education, 2001; 21(2): 93-103. https://doi.org/10.1177/027112140102100203

21.Koegel RL, Werner GA, Vismara LA, Koegel LK. The effectiveness of contextually supported play date interactions between children with autism and typically developing pers. Research and Practice for Persons with Severe Disabilities, 2005; 30(2): 93-102. https://doi.org/10.2511/rpsd.30.2.93

22.Berigel G. 04-06 Examination of the effects of the sport activities on cognitive development of personal care, finegross motor and language for 04-06 age group children with autism [Master Thesis]. Istanbul: Haliç University Institute of Health Sciences; 2015.

23.Alexander MG, Dummer GM, Smeltzer A, Denton SJ. Developing the social skills of young adult Special Olympics athletes. Education and Training in Autism and Developmental Disabilities, 2011; 46: 297-31. 
24.Oriel KN, George CL, Blatt PJ. The impact of a community based exercise program in children and adolescents with disabilities: a pilot study. Physical Disabilities: Education and Related Services, 2008; 27: 5-20.

25.Garcia-Villamisar DA, Dattilo J. Social and clinical effects of a leisure program on adults with Autism spectrum disorder. Research in Autism Spectrum Disorders, 2011; 5(1): 246-253. https://doi.org/10.1016/j.rasd.2010.04.006

26.Gabriels RL, Agnew JA, Holt KD, Shoffner A, Pan Z, Ruzzano S, Mesibov G. Pilot study measuring the effects of therapeutic horseback riding on school-age children and adolescents with autism spectrum disorders. Research in Autism Spectrum Disorders, 2012; 6(2): 578-588. https://doi.org/10.1016/j.rasd.2011.09.007

27.Carter AS, Messinge DS, Stone WL, Celimli S, Nahmias AS, Yoder P. A randomized controlled trial of Hanen's 'More Than Words' in toddlers with early autism symptoms. Journal of Child Psychology and Psychiatry, 2011; 52(7): 741-752. https://doi.org/10.1111/j.1469-7610.2011.02395.x

28. Wong C. A play and joint attention intervention for teachers of young children with autism: A randomized controlled pilot study Autism, 20123; 17(3): 340-357. https://doi.org/10.1177/1362361312474723

29.Barton EE, Wolery M. Training teachers to promote pretend play in young children with disabilities. Exceptional Children, 2010; 77(1): 85-106. https://doi.org/10.1177/001440291007700104

30.Libby ME, Weiss JS, Bancroft S, Ahearn WH. A comparison of most-to-least and least-to-most prompting on the acquisition of solitary play skills. Behaviour Analysis Practice, 2008; 1(1): 37-43. https://doi.org/10.1007/BF03391719

31.Cheldavi H, Shakerian S, Nahid S. The effects of balance training intervention on postural control of children with autism spectrum disorder: Role of sensory information. Research in Autism Spectrum Disorders, 2014; 8(8): 14-18. https://doi.org/10.1016/j.rasd.2013.09.016

32.Kim Y, Todd T, Fujii T. Effects of Taekwondo intervention on balance in children with autism spectrum disorder. Journal of Exercise Rehabilitation, 2019; 12(4): 314-319. https://doi.org/10.12965/jer.1632634.317

33.Najafabadi MG, Sheikh M, Hemayattalab R, Amir M, Rezaii M, Hafizi S. The effect of Spark on social and motor skills of childrenwithautism.PediatricsandNeonatology, 2018;20:1-7. https://doi.org/10.1016/j.pedneo.2017.12.005

34.Piek JP and Dyck MJ. Sensory motor deficits in children with developmental coordination disorder, attention defisit hyperactivity disorder and autistic disorder. Human Mov Sci, 2004; 23: 475-488. https://doi.org/10.1016/j.humov.2004.08.019

35.Dewey D and Hauck JA. Hand preferance and motor functioning in children with autism, Journal of Autism and Developmental Disorders, 2001; 31(3): 265-277. https://doi.org/10.1023/A:1010791118978

36.Fisher AG. Vestibular-proprioceptive pocessing and bilateral integration and sequencing deficits, Sensory integration: theory and practice, Ed.: Fisher AG, Murray EA, Bundy AC, Davis FA, Company, Philadelphia; 1991. P.95-153.

37.Mohamed SE. Effect of Aquatic Exercises Approach (Hallıwick-Therapy) on Motor Skills for Children with Autısm Spectrum Disorders. Ovidius University Annals, Series Physical Education and Sport Science, Movement and Health, 2017;17(2):20-27.

38.Kuno K, Ishii Y, Ueda T, Kurokawa T, Chen Z, Tanaka T, et al. The Effects Of Physical Training On Standing Long Jump Among The People With Autism And The Down Syndrome: 1610. Medicine \& ScienceinSports \& Exercise, 2010;42:335-6. https://doi.org/10.1249/01.MSS.0000384602.87568.7f.

39.Odabas C. The Effects On Invidiual Skills Of Children With Autism In Regular Sports Training [Master Thesis]; 2016.

40.Neophytou N. The efficacy of a 12 week exercise intervention in 11-16 year old adolescent with autism spectrum disorders [Dissertation]. Johannesburg: Centre for Exercise Science and Sports Medicine, School of the Therapeutic Sciences; 2016.

41.Yılmaz I, Yanardag M, Birkan B. Effects of swimming training on physical fitness and water orientation in autism. Pediatrics International, 2004; 46: 624-626. https://doi.org/10.1111/j.1442-200x.2004.01938.x

42.Lloyd M. Investigating the Effectiveness of a Gymnastics Intervention on Motor skills and Balance of Children ages 5-9 with Autism Spectrum Disorder. [Master of Health Sciences]; 2017.

43. Srinivasan SM, Pescatello LS, Bhat AN. Current perspectives on physical activity and exercise recommendations for children and adolescents with autism spectrum disorders, Phys Ther, 2014; 94(6): 875-89. https://doi.org/10.2522/ptj.20130157

44. Sowa $M$ and Meulenbroek $R$. Effects of physical exercise on autism spectrum disorders: a metaanalysis, Res Autism Spect Dis, 2012; 6: 46-57. https://doi.org/10.1016/j.rasd.2011.09.001

45.Parrott KA, Schuster JW, Collins BC and Gassaway LJ. Simultaneous prompting and instructive feedback when teaching chained tasks. Journal of Behavioral Education, 2000; 10(1): 3-19. https://doi.org/10.1023/A:1016639721684

46.Block CC, Sheri RP, Kelly L, Cinnamon SW, Maggie DC. Instructional Approaches That Significantly Increase Reading Comprehension. Journal of Educational Psychology, 2009; 101(2): 262-281. https://doi.org/10.1037/a0014319 


\section{Information about the author:}

Huseyin O.; http://orcid.org/0000-0002-4968-586X; ozturkavrasya@hotmail.com; Gaziantep University School of Physical Education and Sports; Osmangazi neighborhood, University Boulevard, 27310 Şehitkamil, Gaziantep, Turkey.

Cite this article as:

Huseyin O. The impact of sport activities on basic motor skills of children with autism. Pedagogics, psychology, medicalbiological problems of physical training and sports, 2019;23(3):138-144.

https://doi.org/10.15561/18189172.2019.0305

This is an Open Access article distributed under the terms of the Creative Commons Attribution License, which permits unrestricted use, distribution, and reproduction in any medium, provided the original work is properly cited (http://creativecommons.org/licenses/by/4.0/deed.en).

Received: 02.04.2019

Accepted: 29.04.2019; Published: 29.06.2019 